УДК 544.5

\title{
ДЕЙСТВИЕ ГАММА-ОБЛУЧЕНИЯ НА ПАРАМЕТРЫ АКТИВНОСТИ МИКРОПОРОШКОВ АЛЮМИНИЯ
}

\author{
Ильин Александр Петрович1, \\ genchem@mail.ru
}

\author{
Мостовщиков Андрей Владимирович1,2, \\ avmost@tpu.ru
}

Роот Людмила Олеговна1,
tolbanova@mail.ru

Змановский Сергей Владиславович, zmanovskiy@rusal.com

\author{
Смирнова Валентина Владимировна', \\ smirnovavalentinav@mail.ru
}

\author{
Исмаилов Данияр Валерьевич 4 , \\ Ismailov_Daniyar_V@bk.ru
}

Рузиева Гузель Усеиновна4,
guzel.ruzieva@mail.ru

\footnotetext{
1 Национальный исследовательский Томский политехнический университет, Россия, 634050, г. Томск, пр. Ленина, 30.

2 Томский государственный университет систем управления и радиоэлектроники, Россия, 634050, г. Томск, пр. Ленина, 36.

3 ООО «СУАЛ ПМ», Россия, 664064, г. Шелехов, ул. Южная, 2.

4 Казахский национальный университет им. аль-Фараби, Казахстан, 050040, г. Алматы, пр. аль-Фараби, 71.
}

\begin{abstract}
Актуальность исследования. Один из лидеров по производству алюминиевых порошков в России ООО «СУАЛ ПМ» перешел от выпуска грубодисперсных порошков к производству микронных порошков, имеющих более высокую реакционную способность. Микропорошки алюминия применяются во многих отраслях промышленности: порошковой металлургии, самораспространяющемся высокотемпературном синтезе новых материалов, водородной энергетике, пиротехнике и ракетных топливах. Повышение реакционной способности порошков алюминия в различных процессах приводит к понижению энергозатрат и экономии ресурсов.

Цель: получение и объяснение экспериментальных данных по изменению параметров активности микропорошков алюминия после их облучения в зависимости от дозы ү-облучения.

Объекты: микропорошки алюминия АСД-6, АСД-6М.

Методы: диффференциальный термический анализ, рентгенофазовый анализ, методика облучения микропорошков алюминия у-излучением, методика расчета параметров активности порошков алюминия.

Результаты. Получены количественные показатели реакционной способности микропорошков алюминия АСД-6 и АСД-6М до и после облучения ү-излучением изотопа $\mathrm{Co}^{60}$ с энергией 1,17 и 1,33 МэВ, т. е. энергией существенно ниже порога фотояоядерных реакций. Дозы облучения образцов порошков составляли 1, 2, 4, 8 и 10 Мрад. После у-облучения температура начала окисления микропорошков снизилась максимально на 90 и $85{ }^{\circ} \mathrm{C}$; максимальная скорость окисления возросла на 83 и $36 \%$; степень окисленности (при нагревании до $1250^{\circ} \mathrm{C}$ ) повысилась на 5,1 \%, и минимально понизилась на 1,3\% для микропорошков АСД-6 и АСД-6М, соответственно. Удельный тепловой эфрфект окисления после ү-облучения всеми дозами был больше, чем для необлученных порошков. Максимальные значения удельного теплового эфрфекта для АСД-6 на 199,5 кДж/моль, а для АСД-6М - на 134,8 кДж/моль больше тепловых эфффектов, чем для необлученных порошков, что существенно превышает стандартную теплоту плавления алюминия (10,8 кДж/моль). Следовательно, такое состояние системы «алюминий - оксид алюминия» характеризуется запасенной энергией в 9 раз больше стандартной теплоты плавления алюминия, что с позиции классической термодинамики невозможно. В то же время известно, что запасание энергии в нанопорошках происходит за счет формирования двойного электрического слоя в частицах алюминия.
\end{abstract}

\section{Ключевые слова:}

Микропорошки, алюминий, параметры активности, облучение, ү-излучение, запасенная энергия,

теплота плавления, система «алюминий-оксид», термодинамика, энергонасыщенное состояние вещества.

\section{Введение}

Влияние $\beta$-излучения [1] на атомную и молекулярную структуру веществ широко используется зарубежными учеными [2]. Действие низкоэнергетического ионизирующего $\gamma$-излучения галлиевого контура атомного реактора ТПУ [3] на материалы [4] в настоящее время используется для облучения кремния и полупроводниковых приборов для улучшения их характеристик [3-7]. Порошки алюминия входят в состав пиротехнических смесей и твердых ракетных топлив [8]. Переход от грубодисперсных порошков алюминия к высокодисперсным [9] и нанодисперсным порошкам $[10,11]$ привел к новым закономерностям в их свойствах как энергоаккумулирующих веществ $[12,13]$. Действие различных видов ионизирующих излучений на массивные материалы изучено достаточно подробно при строительстве и эксплуатации оборудования атомных реакторов $[4-7,14,15]$. В то же вре- 
мя действие $\gamma$-излучения на микропорошки алюминия осталось практически не изученным $[14,16,17]$.

Целью работы являлось получение и объяснение экспериментальных данных по изменению параметров активности микропорошков алюминия после их облучения в зависимости от дозы $\gamma$-облучения.

\section{Методики экспериментов и характеристики микропорошков алюминия}

В качестве объекта исследования выбраны микропорошки алюминия АСД-6 и АСД-6М производства ООО «СУАЛ ПМ» (г. Шелехов) [18]. Согласно паспортным данным микропорошки имеют следующие характеристики (табл. 1).

Таблица 1. Характеристики микропорошков алюминия $\left(S_{\text {уд }}-\right.$ площадь удельной поверхности, $d_{s}$ среднеповерхностный диаметр частии, $\omega(A l)$ - массовая доля $A l^{0}, h$ - расчетная средняя толщина оксидной пленки)

Table 1. Characteristics of aluminium micro powders $\left(S_{s p}\right.$ - specific surface area, $d_{s}$ - average particle diameter, $\omega(A l)$ - mass fraction of $A l^{0}, h-$ estimated average thickness of the oxide film)

\begin{tabular}{|c|c|c|c|c|}
\hline $\begin{array}{c}\text { Вид порошка } \\
\text { Type of powder }\end{array}$ & $\begin{array}{c}S_{\text {уд }} \mathrm{M}^{2} / \Gamma \\
\left(\mathrm{m}^{2} / \mathrm{g}\right)\end{array}$ & $\begin{array}{c}d_{s}, \text { мкм } \\
(\mathrm{mkm})\end{array}$ & $\begin{array}{c}\omega(\mathrm{Al})^{*} \text { мас. \% } \\
\text { (wt. \%) }\end{array}$ & $\begin{array}{c}h^{*}, \text { нм } \\
(\mathrm{nm})\end{array}$ \\
\hline $\begin{array}{c}\text { ACД-6 } \\
\text { ASD-6 }\end{array}$ & 0,51 & 4,36 & 92 & 15 \\
\hline $\begin{array}{c}\text { ACД-6M } \\
\text { ASD-6M }\end{array}$ & 0,63 & 3,53 & 91 & 12 \\
\hline
\end{tabular}

* параметры порошков после одного года хранения 6 условно-герметичной таре.

* parameters of powders after one year of storage in a relatively airproof containers.

Для облучения микропорошков использовали источник $\gamma$-излучения - изотоп Со ${ }^{60}: 1,17$ и 1,33 МэВ, интенсивность излучения 0,05 Мрад/с. Образцы микропорошков облучали в тонком слое толщиной 2 мм в конвертах из алюминиевой фольги толщиной 8 мкм, облучение проводили на всю глубину порошка. Дозу облучения определяли с помощью стандартной мето- дики по потемнению дозиметрической пленки [19]. При облучении температура поверхности образца не превышала $40^{\circ} \mathrm{C}$.

Для определения реакционной способности микропорошков алюминия применяли дифференциальный термический анализ (ДТА) при линейном повышении температуры со скоростью 10 град/мин в атмосфере воздуха (термоанализатор SDT Q600 фирмы «Instrument») [20]. Для исследований количественной оценки реакционной способности порошков металлов были разработаны четыре параметра их активности [21]: $t_{\text {но }}$ - температура начала окисления, $V_{\max }-$ максимальная скорость окисления, $\alpha$ - степень окисленности порошков и $\Delta H-$ удельный тепловой эффект окисления. В это же время ДТА использовали в качестве метода определения величины запасенной энергии следующим образом: из величины удельного теплового эффекта окисления облученного микропорошка вычитали удельный тепловой эффект этого же порошка до облучения.

\section{Результаты экспериментов}

Параметры активности максимально отражают структурно-энергетическое состояние порошков [22]. Порошки АСД-6 и АСД-6М были подвергнуты $\gamma$ облучению непрерывным излучением $\gamma$-источника $\mathrm{Co}^{60}$ [7]. До и после облучения образцы были подвергнуты ДТА при нагревании в воздухе (рисунок), по результатам которого были рассчитаны параметры активности. В табл. 2 приведена температура начала окисления в зависимости от дозы $\gamma$-облучения.

С увеличением дозы $\gamma$-облучения $t_{\text {но }}$ порошков снижалась: максимальное снижение происходило для АСД-6 и составило $90^{\circ} \mathrm{C}$. Необходимо отметить (табл.

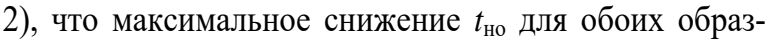
цов наблюдалось при облучении минимальной дозой 1 Мрад. Таким образом, $\gamma$-излучение взаимодействует с оксидной оболочкой частиц микропорошков, в основном снижая ее температурную устойчивость при нагревании порошков в воздухе.
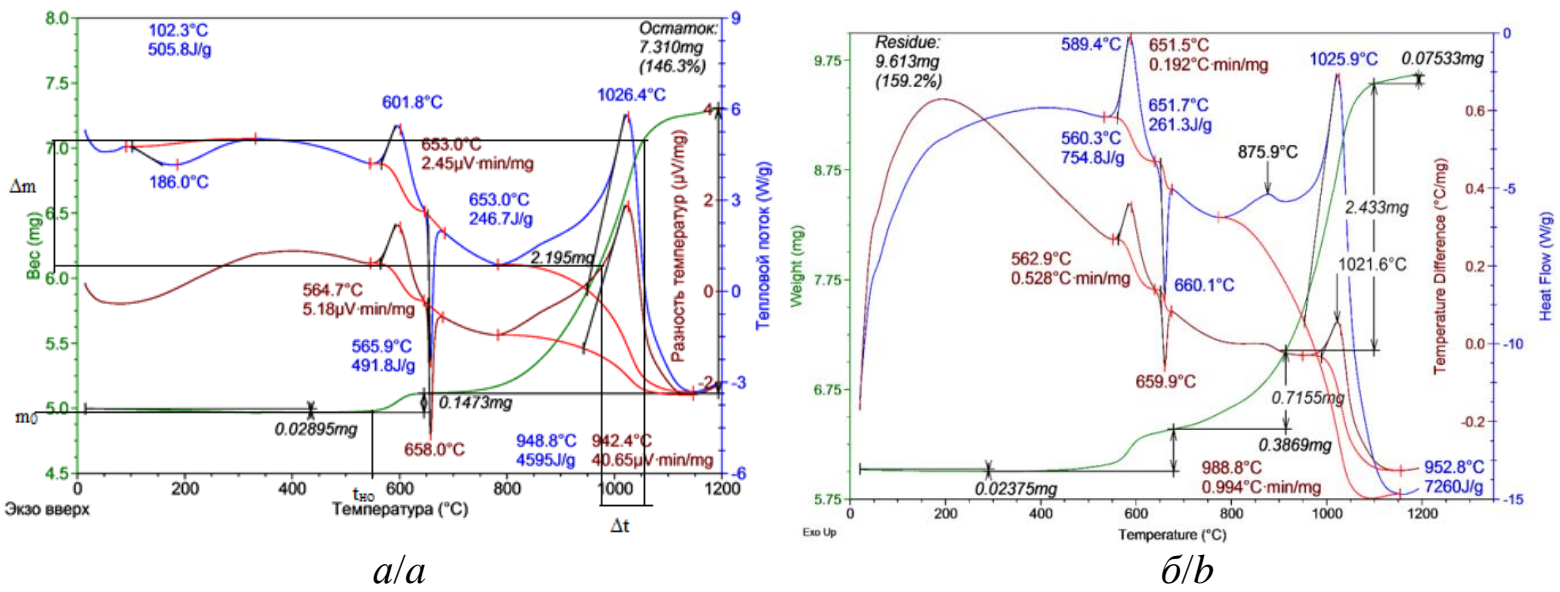

Рисунок. Термограммы микропорошков алюминия АСД-6 (скорость нагрева 10 град/мин, атмосфера - воздух): а) исходный порошок; б) после воздействия $\gamma$-излучением дозой 1 Мрад

Figure. Thermograms of ASD-6 aluminum micropowders (heating rate $10 \mathrm{deg} / \mathrm{min}$, atmosphere - air): a) initial powder; $b$ ) after 1 Mrad $\gamma$-radiation exposure 
Таблица 2. Температура начала окисления $\left(t_{\text {но }}{ }^{\circ} \mathrm{C}\right)$ микронных порошков алюминия после $\gamma$-облучения

Table 2. Oxidation start temperature $\left(t_{o s},{ }^{\circ} \mathrm{C}\right)$ of aluminium micron powders after $\gamma$-radiation exposure

\begin{tabular}{|c|c|c|c|c|c|c|c|}
\hline \multirow{3}{*}{$\begin{array}{c}\text { Вид } \\
\text { порошка } \\
\text { Type of } \\
\text { powder }\end{array}$} & \multicolumn{6}{|c|}{$\begin{array}{l}t_{\text {но }},{ }^{\circ} \mathrm{C} \\
t_{\text {os }},{ }^{\circ} \mathrm{C}\end{array}$} & \multirow{3}{*}{\begin{tabular}{|c} 
Максимальное понижение \\
температуры начала окисле- \\
ния, $\Delta t_{\text {но }},{ }^{\circ} \mathrm{C}$ \\
Maximum decrease of the \\
oxidation start temperature, \\
$\Delta t_{\mathrm{os}},{ }^{\circ} \mathrm{C}$ \\
\end{tabular}} \\
\hline & \multicolumn{6}{|c|}{$\begin{array}{c}\text { Доза } \gamma \text {-облучения, Мрад } \\
\gamma \text {-radiation exposure, Mrad }\end{array}$} & \\
\hline & 0 & & 2 & 4 & 8 & & \\
\hline $\begin{array}{l}\text { АСД-6 } \\
\text { ASD-6 }\end{array}$ & 550 & 460 & 530 & 548 & 549 & 460 & 90 \\
\hline $\begin{array}{l}\text { АСД-6M } \\
\text { ASD-6M }\end{array}$ & 530 & 445 & 475 & 510 & 524 & 475 & 85 \\
\hline
\end{tabular}

Максимальное увеличение скорости окисления $V_{\max }$ для микропорошка АСД-6 наблюдали после $\gamma$ облучения максимальной дозой 10 Мрад (на $83 \%$ ), в то время как максимальную $V_{\max }$ для микропорошка АСД-6М наблюдали после облучения минимальной дозой 1 Мрад (на 36 \%). Результаты экспериментов приведены в табл. 3.

Таблица 3. Максимальная скорость окисления ( $V_{\max }$ мг/мин) микронных порошков алюминия после ү-облучения

Table 3. Maximal oxidation rate $\left(V_{\operatorname{mav}} \mathrm{mg} / \mathrm{min}\right)$ of aluminium micron powders after $\gamma$-radiation exposure

\begin{tabular}{|c|c|c|c|c|c|c|c|}
\hline \multirow{3}{*}{$\begin{array}{l}\text { Вид порошка } \\
\text { Type of } \\
\text { powder }\end{array}$} & \multirow{2}{*}{\multicolumn{6}{|c|}{$\begin{array}{c}V_{\max }, \text { мг/мин }(\mathrm{mg} / \mathrm{min}) \\
\text { Доза } \gamma \text {-облучения, Мрад } \\
\gamma \text {-radiation exposure, Mrad }\end{array}$}} & \multirow{3}{*}{$\begin{array}{c}\Delta V_{\max }, \text { мг/мин } \\
(\mathrm{mg} / \mathrm{min})\end{array}$} \\
\hline & & & & & & & \\
\hline & 0 & 1 & 2 & 4 & 8 & 10 & \\
\hline $\begin{array}{l}\text { АСД-6 } \\
\text { ASD-6 }\end{array}$ & 0,12 & 0,21 & 0,18 & 0,19 & 0,14 & 0,22 & 0,10 \\
\hline $\begin{array}{l}\text { АСД-6M } \\
\text { ASD-6M }\end{array}$ & 0,14 & 0,16 & 0,11 & 0,10 & 0,17 & 0,19 & 0,05 \\
\hline
\end{tabular}

Согласно полученным данным (табл. 3) облучение микропорошка алюминия АСД-6 всеми дозами привело к увеличению скорости окисления. При облучении микропорошка АСД-6М после воздействия $\gamma$-излучения дозами 2 и 4 Мрад максимальная скорость окисления максимально снизилась на $30 \%$.

В зависимости от дозы облучения степень окисленности порошка АСД-6 повышалась и понижалась, достигая максимума после облучения дозой 10 Мрад: повысилась на 5,1 \% (табл. 4). Степень окисленности порошка АСД-6М при нагревании в воздухе после $\gamma$-облучения всеми дозами в изучаемом диапазоне понизилась и имела максимальное значение - на 1,3\% меньше, чем $\alpha$ исходного порошка. Максимальное понижение $\alpha$ порошка АСД-6М на 52,4 \% произошло после облучения дозой 1 Мрад.

Таблица 4. Степень окисленности ( $\alpha$, \%) микронных порошков алюминия после $\gamma$-облучения

Table 4. Oxidation degree $(\alpha, \%)$ of aluminium micron powders after $\gamma$-radiation exposure

\begin{tabular}{|c|c|c|c|c|c|c|c|}
\hline \multirow{3}{*}{$\begin{array}{l}\text { Вид порошка } \\
\text { Type of powder }\end{array}$} & \multicolumn{6}{|c|}{$\alpha, \%$ (до $\left.1250{ }^{\circ} \mathrm{C}\right) /\left(\right.$ up to $\left.1250^{\circ} \mathrm{C}\right)$} & \multirow{3}{*}{$\Delta \alpha_{\max }, \%$} \\
\hline & \multicolumn{6}{|c|}{$\begin{array}{c}\text { Доза } \gamma \text {-облучения, Мрад } \\
\gamma \text {-radiation exposure, Mrad }\end{array}$} & \\
\hline & 0 & 1 & 2 & 4 & 8 & 10 & \\
\hline АСД-6/ASD-6 & 21,3 & 23,8 & 17,9 & 20,8 & 22,8 & 26,4 & 5,1 \\
\hline АСД-6M/ASD-6M & 23,3 & 11,0 & 16,9 & 13,3 & 18,1 & 22,0 & $-1,3$ \\
\hline
\end{tabular}

Величины тепловых эффектов окисления образцов микропорошков алюминия до и после $\gamma$-облучения приведены в табл. 5. В зависимости от дозы облучения тепловой эффект окисления микропорошка АСД-6 только увеличивался, достигая максимального значения после облучения дозой 10 Мрад 199,5 кДж/моль.

Таблица 5. Удельный тепловой эффект окисления (АН, кДж/моль) микронных порошков алюминия после их $\gamma$-облучения

Table 5. Specific heat effect of oxidation $(\Delta H, \mathrm{~kJ} / \mathrm{mol})$ of aluminium micron powders after $\gamma$-radiation exposure

\begin{tabular}{|c|c|c|c|c|c|c|c|}
\hline \multirow{3}{*}{$\begin{array}{c}\text { Вид } \\
\text { порошка } \\
\text { Type of } \\
\text { powder } \\
\end{array}$} & \multicolumn{6}{|c|}{$\Delta H$, кДж/моль $(\mathrm{kJ} / \mathrm{mol})$} & \multirow{3}{*}{$\begin{array}{c}\Delta H_{\max }, \\
\text { кДж/моль } \\
(\mathrm{kJ} / \mathrm{mol})\end{array}$} \\
\hline & \multicolumn{6}{|c|}{$\begin{array}{c}\text { Доза } \gamma \text {-облучения, Мрад } \\
\gamma \text {-radiation exposure, Mrad }\end{array}$} & \\
\hline & 0 & 1 & 2 & 4 & 8 & 10 & \\
\hline $\begin{array}{l}\text { АСД-6 } \\
\text { ASD-6 }\end{array}$ & 117,8 & 209,4 & 148,4 & 277,4 & 120,7 & 317,3 & 199,5 \\
\hline $\begin{array}{l}\text { АСД-6M } \\
\text { ASD-6M }\end{array}$ & 121,2 & 110,8 & 93,7 & 113,1 & 85,0 & 261,0 & 139,8 \\
\hline
\end{tabular}

В то же время после облучения тепловой эффект окисления микропорошка алюминия АСД-6М уменьшался за исключением дозы облучения 10 рад, после действия которой тепловой эффект повысился на 139,8 кДж/моль (табл. 5).

\section{Обсуждение результатов}

Микропорошки АСД-6 и АСД-6М по величинам площади удельной поверхности сразу после получения различались на $23,5 \%$. После одного года хранения на частицах порошка АСД-6М толщина оксидной пленки была меньше примерно на 30 \% в сравнении с оболочкой на частицах порошка АСД-6. Снижение температуры начала окисления алюминия (частиц микропорошков) связано со снижением термической стабильности оксидной пленки после действия $\gamma$-излучения. При общей тенденции к снижению температуры начала окисления после $\gamma$-облучения при некоторых дозах облучения происходил отжиг дефектов в защитной пленке и повышение ее термостабильности (табл. 2).

Повышение удельного теплового эффекта (табл. 5) с эмиссией запасенной энергии происходит после разрушения двойного электрического слоя, ранее сформированного $\gamma$-излучением [23]. Таким образом, при $\gamma$-облучении происходило образование лавин электронов, их торможение и взаимодействие с ионами $\mathrm{Al}^{3+}$ в решетке $\mathrm{Al}_{2} \mathrm{O}_{3}$ и $\mathrm{Al}(\mathrm{OH})_{3}$, их восстановление до $\mathrm{Al}^{0}$ с образованием кластеров алюминия $\mathrm{Al}_{n}$ в защитной оболочке $[24,25]$. При облучении $\gamma-\mathrm{Al}_{2} \mathrm{O}_{3}$, синтезированного из $\mathrm{Al}(\mathrm{OH})_{3}$, выход кластеров $\mathrm{Al}_{n}$ оказался низким (менее 3 мас. \%), что не позволило внедрить способ в практику получения водорода [24]. Для частицы алюминия диаметром 100 мкм максимальная толщина защитной оболочки составляет 10 нм [23]. Массовая доля оксида алюминия в частицах алюминия составляет 6-8\%. Таким образом, вклад в повышение теплового эффекта за счет окисления кластеров после $\gamma$-облучения порошков не превышает 8-9 \%. 
При нагревании в воздухе $\gamma$-облученных образцов порошков алюминия АСД-6 не происходили колебательные процессы: только повышение $V_{\max }$ максимально с 0,12 до 0,22 мг/мин после облучения дозой 10 Мрад (табл. 3). После $\gamma$-облучения более дисперсного порошка АСД-6М происходило как повышение, так и понижение $V_{\max }$. После облучения дозой 10 Мрад $V_{\max }$ возросла на 0,05 мг/мин. Такое изменение параметра активности объясняется изменением термической стабильности защитной оксидной пленки $\left(t_{\text {но }}\right)$.

После $\gamma$-облучения микропорошков алюминия АСД-6 дозами от 1 до 10 Мрад тепловой эффект окисления (табл. 5) только увеличивался, достигая максимального значения (261 кДж/моль) после облучения дозой 10 Мрад. В сравнении с необлученным порошком удельный тепловой эффект окисления увеличился на 199,5 кДж/моль.

После облучения микропорошка АСД-6М дозами 1, 2, 4 и 8 Мрад удельный тепловой эффект окисления был ниже удельного теплового эффекта необлученного порошка, но после облучения дозой 10 Мрад удельный тепловой эффект окисления увеличился с 121,2 до 261,0 кДж/моль, т. е. на 139,8 кДж/моль. Ранее такой эффект наблюдали после облучения нанопорошков металлов $\beta$-излучением и СВЧ-излучением $[26,27]$. Вероятной причиной запасания энергии порошками металлов является формирование или усиление под действием $\gamma$-излучения двойного электрического слоя [23], как и в случае действия $\beta$-излучения на эти порошки [28].

\section{Выводы}

1. Полученный экспериментальный результат объясняется формированием двойного электрического слоя под действием $\gamma$-облучения в поверхностном и приповерхностных слоях частиц алюминия,

\section{СПИСОК ЛИТЕРАТУРЫ}

1. Bing-She Xu, Shun-Ichiro Tanaka. Behavior and bonding mechanisms of aluminum nanoparticles by electron beam irradiation // Nanostructured Materials. - 1999. - V. 12. - P. 915-918.

2. Gordon W.F. Drake, Jung-Sik Yoon, Daiji Kato G.K. Atomic and molecular data and their applications // European Physical Journal. - 2018. - V. 72. - № 3. - P. 140-142.

3. Application of NANOcolloid materials labeled by radionuclides in medicine / V.S. Skuridin, E.S. Stasyuk, A.S. Rogov, V.L. Sadkin, N.V. Varlamova, E.A. Nesterov // Advanced Materials Research: Radiation and nuclear techniques in material science: Scientific Journal. - 2015. - V. 1084. - P. 352-356.

4. Воробьев А.А., Завадовская Е.К., Головчанский Е.М. Запасенная энергия в щелочногалоидных кристаллах // Известия Томского политехнического института. - 1969. - Т. 170. - С. 8-24.

5. Harneet Kaur Sidana, Rameez Ahmad Mir, Pandey O.P. Synthesis of molybdenum nitride (Mo2N) nanoflakes via in-situ reductionnitridation // Journal of Alloys and Compounds. - 2018. V. 736. - P. 255-265.

6. Korchagin M.A., Zarko V.E., Bulina N.V. Synthesis of nanocrystalline magnesium and aluminum diborides // Eurasian ChemicoTechnological Journal. - 2017. - V. 19. - № 3. - P. 209-213.

7. Standish N., Worner H. Microwave application in the reduction of metal oxides with carbon // The Journal of Microwave Power and Electromagnetic Energy. - 1990. - V. 25. - Iss. 3. - P. 177-180.

8. Microstructure effects in aluminized solid rocket propellants L.T. DeLuca, L. Galfetti, G. Colombo, F. Maggi, A. Bandera, V.A. Babuk, V.P. Sinditskii // Journal of Propulsion and Power. 2010. - V. 26. - № 4. - P. 724-732. в которых энергия запасается необратимо, по механизму псевдоемкости. Альтернатива предложенному объяснению в настоящее время в литературе отсутствует.

2. Облучение микропорошков алюминия АСД-6, АСД-6М потоком $\gamma$-излучения приводило к повышению запасенной энергии максимально на 199,5 кДж/моль, что в 17,5 раз больше стандартной теплоты плавления алюминия. Таким образом, облученные микропорошки имеют преимущества в таких процессах, как неорганический синтез, горение, спекание, приготовление металлокерамики и др. Алюминий в виде микропорошков необходимо рассматривать не как компактный материал, а как композиционный материал - алюминийоксид алюминия. В этом случае облучение микропорошков $\gamma$-излучением является тестом на характеристики композитов.

3. Облучение микропорошков алюминия АСД-6, АСД-6М $\gamma$-излучением приводило к повышению их реакционной способности: снижалась температура начала окисления максимально на $90{ }^{\circ} \mathrm{C}$ (АСД-6, 1 Мрад), увеличивалась максимальная скорость окисления максимально на 83 \% (АСД-6, 10 Мрад), степень окисленности также увеличивалась максимально на 24 \% (АСД-6, 10 Мрад) и повышался удельный тепловой эффект окисления максимально на 170 \% (АСД-6, 10 Мрад).

Исследование выполнено в Томском политехническом университете в рамках программы повымения конкурентоспособности Томского политехнического университета (средства ВИУ).

Работа выполнена при финансовой поддержке Российского фонда фундаментальных исследований, грант № 19-03-00160.

9. Nanocomposite thermite powders with improved flowability prepared by mechanical milling / Quang Nguyen, Ci Huang, Mirko Schoenitz, K.T. Sullivan, E.L. Dreizin // Powder Technology. - 2018. - V. 327. - P. 368-380.

10. Морохов И.Д., Трусов Л.И., Чижик С.П. Ультрадисперсные металлические среды. - М.: Атомиздат, 1977. - 264 с.

11. Gleiter H. Nanocrystalline materials // Progress in Materials Science. - 1989. - V. 33. - № 4. - P. 223-315.

12. Kinetic model of $\mathrm{Al}$ oxidation by water vapor in heterogeneous plasma: Heterophase kinetics / V.A. Bityurin, A.I. Klimov, O.V. Korshunov, V.F. Chinnov // High Temperature. - 2015. V. 53. - № 1. - P. 21-26.

13. Марчук Г.И., Образцов И.Ф., Седов Л.И. Научные основы прогрессивной техники и технологии. - М.: Машиностроение, 1986. $-376 \mathrm{c}$

14. Mills K.C., Dächer C.-Å. The casting powders book. - Berlin; London; Paris: Springer Int. Publishing AG, 2017. $-550 \mathrm{p}$

15. Рыкалин Н.Н., Углов А.А. Тепло- и массоперенос при электронно-лучевой обработке // Промышленная теплотехника. 1981. - T. 3. - № 5. - C. 3-16.

16. Рыкалин Н.Н., Зуев И.В., Углов А.А. Основы электроннолучевой обработки материалов. - М.: Машиностроение: 1978. $-239 \mathrm{c}$.

17. Воздействие концентрированных потоков энергии на материалы / под ред. акад. Н.Н. Рыкалина. - М.: Наука, 1985. - 246 с.

18. ТУ 1791-007-49421776-2011. Порошки алюминиевые АСД. Город: Шелехов, Изд-во ООО «СУАЛ ПМ». - 7 с.

19. Химическая энциклопедия / под ред. акад. И.П. Кнуянц. Т. 2. - М.: Советская энциклопедия, 1990. - С. 219-221. 
20. Wendlandt W.W. Thermal methods of analysis. 2nd ed. - NY: John Wiley \& Sons, 1974. -524 p.

21. Characterization of aluminum powders. I. Parameters of reactivity of aluminium powders / A. Ilyin, A. Gromov, V. An et al. // Propellants, Explosives, Pyrotechnics. - 2002. - V. 27. - № 6. P. 361-364

22. Allen D., Krier H., Glumac N. Heat transfer effects in nanoaluminum combustion at high temperatures // Combustion and Flame. - 2014. - V. 161. - Iss. 1. - P. 295-302.

23. Ильин А.П. Развитие электровзрывной технологии получения нанопорошков в НИИ высоких напряжений при Томском политехническом университете // Известия томского политехнического университета. - 2003. - Т. 306. - № 1. - С. 133-139.

24. Standish N., Worner H. Microwave application in the reduction of metal oxides with carbon // Journal of Microwave Power and Electromagnetic Energy. - 1990. - V. 25 (3). - P. 177-180.
25. Bonevich J.E., Marks L.D. Electron radiation damage of $\alpha$ alumina // Ultramicroscopy. - 1991. - V. 35. - P. 161-166.

26. Microwave heating characteristics of magnetite ore / R. Rajavaram, J. Lee, J.S. Oh, H.G. Kim, J. Lee // Metals and Materials International. - 2016. - V. 22. - Iss. 6. - P. 1116-1120.

27. Perov V.V., Zarko V.E., Zhukov A.S. New microwave method for measuring unsteady mass gasification rate of condensed systems // Combustion, Explosion, and Shock Waves. - 2014. - V. 50. № 6. - P. 739-741.

28. Влияние бета-облучения на параметры активности микропорошков алюминия / А.П. Ильин, А.В. Мостовщиков, Л.О. Роот и др. // Известия Томского политехнического университета. Инжиниринг георесурсов. - 2019. - Т. 330. - № 8. - С. 87-93.

Поступила 27.12.2019 г.

\section{Информация об авторах}

Ильин А.П., доктор физико-математических наук, профессор отделения естественных наук Школы базовой инженерной подготовки Национального исследовательского Томского политехнического университета.

Мостовщиков $\boldsymbol{A . B . , ~ к а н д и д а т ~ т е х н и ч е с к и х ~ н а у к , ~ с т а р ш и и ̆ ~ н а у ч н ы и ̆ ~ с о т р у д н и к ~ н а у ч н о - и с с л е д о в а т е л ь с к о и ̆ ~ л а - ~}$ боратории СВЧ-технологий Инженерной школы ядерных технологий Национального исследовательского Томского политехнического университета; доцент кафедры физической электроники Факультета электронной техники Томского государственного университета систем управления и радиоэлектроники.

Poom Л.O., кандидат технических наук, старший преподаватель отделения естественных наук Школы базовой инженерной подготовки Национального исследовательского Томского политехнического университета.

Змановский $\boldsymbol{C . B .}$, кандидат технических наук, директор Центра инноваций ООО «СУАЛ ПМ».

Cмирнова B.B., кандидат технических наук, старший преподаватель отделения естественных наук Школы базовой инженерной подготовки Национального исследовательского Томского политехнического университета.

Исмаилов Д.В., аспирант Казахского национального университета им. аль-Фараби.

Рузиева Г.У., магистрант Казахского национального университета им. аль-Фараби. 
UDC 544.5

\section{IMPACT OF GAMMA-RADIATION EXPOSURE ON ACTIVITY PARAMETERS OF ALUMINIUM MICROPOWDERS}

Alexander P. llyin ${ }^{1}$,
genchem@mail.ru

Andrey V. Mostovshchikov1,2, avmost@tpu.ru

Liudmila 0. Root ${ }^{1}$, tolbanova@mail.ru

\section{Sergey V. Zmanovskiy ${ }^{3}$,} zmanovskiy@rusal.com

1 National Research Tomsk Polytechnic University, 30, Lenin avenue, Tomsk, 634050, Russia.

2 Tomsk State University of Control Systems and Radioelectronics, 36, Lenin avenue, Tomsk, 634050, Russia.

3 OOO SUAL PM,

2, Yuzhnaya street, Shelekhov, 664064, Russia.

4 Al-Farabi Kazakh National University,

71, al-Farabi avenue, Almaty, 050040, Kazakhstan.
Valentina V. Smirnova ${ }^{1}$, smirnovavalentinav@mail.ru

Daniyar V. Ismailov4, Ismailov_Daniyar_V@bk.ru

Guzel U. Ruzieva ${ }^{4}$, guzel.ruzieva@mail.ru

The relevance of the research. One of the leaders in production of aluminum powders in Russia 000 «SUAL-PM» has passed from production of coarse powders to production of micron powders with higher reactivity. Aluminium micropowders are used in many branches of industry: powder metallurgy, self-propagating high-temperature synthesis of new materials, hydrogen energy, pyrotechnics and rocket fuels. Increase of aluminium powders reactivity in various processes leads to reduction in energy consumption and resource saving.

The main aim of the research was to obtain and explain experimental data on changes in activity parameters of aluminium micropowders after radiation exposure, depending on the $y$-radiation dose.

Objects: micron-scaled aluminium powders ASD-6, ASD-6M.

Methods: differential thermal analysis, $X$-ray diffraction analysis, method of aluminium micropowders exposure with $y$-radiation, method of calculation of the activity parameters of aluminium powders.

Results. Quantitative indicators of the reactivity of aluminium micropowders ASD-6 and ASD-6M before and after exposure with $y$-radiation were obtained. The radiation source was the $\mathrm{Co}^{60}$ isotope with the energy of 1,17 and 1,33 MeV, i. e. the energy substantially below the threshold of photonuclear reactions. The doses to the powder samples exposure were 1, 2, 4, 8, and $10 \mathrm{Mrad}$. After $y$-radiation exposure the micropowders oxidation start temperature has maximally decreased on 90 and $85^{\circ} \mathrm{C}$; maximal oxidation rate increased by 83 and $36 \%$; the degree of oxidation (at heating up to $1250{ }^{\circ} \mathrm{C}$ ) increased by $5,1 \%$, and minimally decreased by $1,3 \%$ for the ASD-6 and the ASD-6M micropowders, accordingly. The specific thermal effect of oxidation after $y$-radiation exposure with all doses was greater than for non-exposed powders; the maximum values of the specific thermal effect was on 199,5 kJ/mol for ASD-6, and 134,8 kJ/mol for ASD$6 \mathrm{M}$ higher than thermal effects for non-exposed powders, which significantly exceeds the standard heat of aluminium melting $(10,8 \mathrm{~kJ} / \mathrm{mol})$. Consequently, such a state of the "aluminium - aluminium oxide» system is characterized by the stored energy, 9 times higher than the standard heat of aluminium melting, which is impossible according to thermodynamics. At the same time, it is known that energy is stored in nanopowders due to the formation of a double electric layer in aluminium particles.

\section{Key words:}

Micropowders, aluminium, activity parameters, exposure, $y$-radiation, stored energy, melting heat, "aluminium - aluminium oxide» system, thermodynamics, energy-saturated state of matter.

The research was carried out at Tomsk Polytechnic University within the Program of Enhancing Competitiveness of Tomsk Polytechnic University (VIU funds).

This work was financially supported by the Russian Fund of Fundamental Investigations, Project No. 19-03-00160.

\section{REFERENCES}

1. Bing-She $\mathrm{Xu}$, Shun-Ichiro Tanaka. Behavior and bonding mechanisms of aluminum nanoparticles by electron beam irradiation. Nanostructured Materials, 1999, vol. 12, pp. 915-918.

2. Gordon W.F. Drake, Jung-Sik Yoon, Daiji Kato G.K. Atomic and molecular data and their applications. European Physical Journal, 2018, vol. 72, no. 3, pp. 140-142.
3. Skuridin V.S., Stasyuk E.S., Rogov A.S., Sadkin V.L., Varlamova N.V., Nesterov E.A. Application of NANOcolloid materials labeled by radionuclides in medicine. Advanced Materials Research: Radiation and nuclear techniques in material science: Scientific Journal, 2015, vol. 1084, pp. 352-356.

4. Vorobyev A.A., Zavadovskaya E.K., Golovchanskiy E.M. The stored energy in alkaline halide crystals. Bulletin of Tomsk Polytechnic Institute, 1969, vol. 170, pp. 8-24. In Rus. 
5. Harneet Kaur Sidana, Rameez Ahmad Mir, Pandey O.P. Synthesis of molybdenum nitride $\left(\mathrm{Mo}_{2} \mathrm{~N}\right)$ nanoflakes via in-situ reductionnitridation. Journal of Alloys and Compounds, 2018, vol. 736, pp. $255-265$.

6. Korchagin M.A., Zarko V.E., Bulina N.V. Synthesis of nanocrystalline magnesium and aluminum diborides. Eurasian Chemico-Technological Journal, 2017, vol. 19, no. 3, pp. 209-213

7. Standish N., Worner H. Microwave application in the reduction of metal oxides with carbon. The Journal of Microwave Power and Electromagnetic Energy, 1990, vol. 25, Iss. 3, pp. 177-180.

8. DeLuca L.T., Galfetti L., Colombo G., Maggi F., Bandera A., Babuk V.A., Sinditskii V.P. Microstructure effects in aluminized solid rocket propellants. Journal of Propulsion and Power, 2010, vol. 26, no. 4, pp. 724-732.

9. Quang Nguyen, Ci Huang, Mirko Schoenitz, Sullivan K.T. Dreizin E.L.. Nanocomposite thermite powders with improved flowability prepared by mechanical milling. Powder Technology, 2018, vol. 327, pp. 368-380.

10. Morokhov I.D., Trusov L.I., Chizhik S.P. Ultradispersnye metallicheskie sredy [Ultrafine metal media]. Moscow, Atomizdat Publ., 1977. 264 p.

11. Gleiter H. Nanocrystalline materials. Progress in Materials Science, 1989, vol. 33, no. 4, pp. 223-315.

12. Bityurin V.A., Klimov A.I., Korshunov O.V., Chinnov V.F. Kinetic model of $\mathrm{Al}$ oxidation by water vapor in heterogeneous plasma: Heterophase kinetics. High Temperature, 2015, vol. 53, no. 1, pp. 21-26.

13. Marchuk G.I., Obraztsov I.F., Sedov L.I. Nauchnye osnovy progressivnoy tekhniki $i$ tekhnologii [Scientific basis of progressive engineering and technologies]. Moscow, Mashinostroenie Publ., 1986. 376 p.

14. Mills K.C., Dächer C.-Å. The casting powders book. Berlin; London; Paris, Springer Int. Publishing AG, 2017. 550 p.

15. Rykalin N.N., Uglov A.A. Teplo- i massoperenos pri elektronnoluchevoy obrabotke [Heat and mass transfer during electron-beam processing]. Promyshlennaya teplotekhnika, 1981, vol. 3, no 5, pp. 3-16.

16. Rykalin N.N., Zuev I.V., Uglov A.A. Osnovy elektronno-luchevoy obrabotki materialov [Fundamentals of electron-beam material processing]. Moscow, Mashinostroenie Publ., 1978. 239 p.
17. Vozdeystvie kontsentrirovannykh potokov energii na materialy [The impact of concentrated energy flow on materials]. Ed. by Acad. N.N. Rykalin. Moscow, Nauka Publ., 1985. 246 p.

18. TU 1791-007-49421776-2011. Poroshki alyuminievye ASD [Product Specifications 1791-007-49421776-2011. Aluminum fine powder]. Shelekhov, OOO «SUAL PM» Pres, 2011. 7 p.

19. Khimicheskaya entsiklopediya [Chemical encyclopedia]. Ed. by acad. I.P. Knuyants. Moscow, Sovetskaya entsiklopediya Publ., 1990. Vol. 2, pp. 219-221.

20. Wendlandt W.W. Themal methods of analysis. $2^{\text {nd }}$ ed. NY, John Wiley \& Sons, 1974. $524 \mathrm{p}$.

21. Ilyin A., Gromov A., An V. Characterization of aluminum powders. I. Parameters of reactivity of aluminium powders. Propellants, Explosives, Pyrotechnics, 2002, vol. 27, no. 6, pp. 361-364.

22. Allen D., Krier H., Glumac N. Heat transfer effects in nanoaluminum combustion at high temperatures. Combustion and Flame, 2014, vol. 161, Iss. 1, pp. 295-302.

23. Ilyin A.P. Development of electric explosive technology for nanopowders production in the High Voltage Research Institute at Tomsk Polytechnic University. Bulletin of the Tomsk Polytechnic University, 2003, vol. 306, no. 1, pp. 133-139. In Rus.

24. Standish N., Worner H. Microwave application in the reduction of metal oxides with carbon. Journal of Microwave Power and Electromagnetic Energy, 1990, vol. 25 (3), pp. 177-180.

25. Bonevich J.E., Marks L.D. Electron radiation damage of $\alpha$ alumina. Ultramicroscopy, 1991, vol. 35, pp. 161-166.

26. Rajavaram R., Lee J., Oh J.S., Kim H.G., Lee J. Microwave heating characteristics of magnetite ore. Metals and Materials International, 2016, vol. 22, Iss. 6, pp. 1116-1120.

27. Perov V.V., Zarko V.E., Zhukov A.S. New microwave method for measuring unsteady mass gasification rate of condensed systems. Combustion, Explosion, and Shock Waves, 2014, vol. 50, no. 6, pp. 739-741.

28. Ilyin A.P., Mostovshchikov A.V., Root L.O. Effect of betaradiation exposure on the parameters of aluminium micropowders activity. Bulletin of the Tomsk Polytechnic University. Geo Assets Engineering, 2019, vol. 330, no. 8, pp. 87-93. In Rus.

Received: 27 December 2019.

\section{Information about the authors}

Alexander P. Ilyin, Dr. Sc., professor, National Research Tomsk Polytechnic University.

Andrei V. Mostovshchikov, Cand. Sc., senior researcher, National Research Tomsk Polytechnic University; associate professor, Tomsk State University of Control Systems and Radioelectronics

Liudmila O. Root, Cand. Sc., senior lecturer, National Research Tomsk Polytechnic University.

Sergey V. Zmanovskiy, Cand. Sc., head of Innovation Centre OOO «SUAL PM».

Valentina V. Smirnova, Cand. Sc., senior lecturer, National Research Tomsk Polytechnic University.

Daniyar V. Ismailov, postgraduate student, Al-Farabi Kazakh National University.

Guzel U. Ruzieva, student, Al-Farabi Kazakh National University. 